\title{
A performance de incubadoras empresariais do interior paulista à luz de um novo modelo de avaliação de desempenho
}

\author{
Charbel Jabbour (USP) cjabbour@prod.eesc.usp.br \\ Sergio Azevedo Fonseca (UNESP) saf@fclar.unesp.br
}

\begin{abstract}
Resumo
Este texto apresenta uma nova proposta para a avaliação de desempenho de incubadoras empresariais mistas. Para a formulação deste construto teórico, partiu-se da contribuição de Fonseca (2000), somando-se a esta as principais proposições da literatura especializada, ainda que escassa. A validade desse modelo foi testada em duas incubadoras do interior paulista, cujas performances são analisadas em perspectiva comparada. Os dados, primários e secundários foram coletados de múltiplas formas e analisados com base na metodologia da Escada da Abstração Analítica. Os resultados indicam que os indicadores ora apresentados estão aptos a avaliar o desempenho das incubadoras empresariais; indicam também que há discrepância entre o desempenho das incubadoras analisadas.

Palavras chave: Incubadoras empresariais, Avaliação de desempenho.
\end{abstract}

\section{Introdução}

O movimento brasileiro de incubadoras de empresas se expandiu nas últimas duas décadas, demandando grandes montantes de recursos públicos para sua consolidação, fato que aumenta a importância de mecanismos capazes de avaliar o desempenho dessas organizações, fornecendo informações confiáveis às instituições mantenedoras. Entretanto, quanto mais se avança no debate sobre a expansão e importância das incubadoras empresariais, mais aparente se torna uma lacuna observável na literatura especializada: modelos orientados para a avaliação da performance de incubadoras mistas.

Com base nessa inquietação, conduziu-se, com apoio da FAPESP, um projeto de investigação dedicado à proposição de um construto teórico capaz de fornecer bases para a avaliação do desempenho de incubadoras empresariais mistas. $\mathrm{O}$ teste do mecanismo proposto foi realizado em duas incubadoras do interior paulista, buscando fornecer as bases para uma avaliação comparada do desempenho a partir da performance dessas unidades.

Os resultados do estudo realizado são expostos a seguir. Parte-se de uma breve explanação sobre a gênese, expansão e tipologia das incubadoras empresariais. Na seqüência, é feita uma breve exposição dos principais modelos encontrados na literatura, propostos para a avaliação do desempenho de incubadoras. Os tópicos 4, 5, 6 e 7 discutem, respectivamente, os materiais e métodos de pesquisa; o construto teórico desenvolvido; o teste de sua aplicabilidade nas incubadoras estudadas; e as considerações finais, indicando novas oportunidades de pesquisa.

\section{Incubadoras empresariais: definição, tipologia e expansão}

No contexto econômico atual, de globalização dos mercados e das relações entre os agentes neles presentes, as organizações produtivas vêem-se frente a um esforço crescente na busca da competitividade. Reconfiguram-se sistemas produtivos e as próprias formas de competição entre os agentes econômicos; avolumam-se as redes de organizações; redefine-se o papel que o Estado deve desempenhar nesse contexto; sobressai a necessidade da criação de mecanismos multifacetados, capazes de estimular e apoiar a atividade empreendedora, como forma de assegurar a manutenção de níveis adequados de emprego nas mais diferentes 
economias; destaca-se a importância dessa atividade empreendedora, assim como do universo das micro e pequenas empresas, para a geração e a difusão de inovações. Uma das conseqüências dessas intensas e profundas transformações é o surgimento, e a consolidação nas últimas duas décadas, de novas formas organizacionais capazes de oferecer suporte aos elos mais fracos da cadeia econômica e de, simultaneamente, estimular inovações (KAHANE e TZVI, 2005).

No Brasil, o Governo Federal (MCT, 1998), atento a esse ambiente turbulento, passa a apoiar o movimento de incubadoras de empresas como forma de consolidar mecanismos e arranjos institucionais/empresariais capazes de viabilizar a transformação do conhecimento em produtos, processos e serviços. Em um contexto onde o conhecimento, a eficiência e a rapidez no processo de inovação passam a ser reconhecidamente os elementos decisivos para a competitividade das economias, o processo de incubação é crucial para que a inovação se concretize em tempo hábil para suprir as demandas do mercado (MCT, 1998, p.4).

O Ministério da Ciência e Tecnologia do Governo Federal, através do Programa Nacional de Apoio a Incubadoras de Empresas (PNI), define que uma incubadora é um mecanismo que estimula a criação e o desenvolvimento de micro e pequenas empresas industriais ou de prestação de serviços, de base tecnológica ou de manufaturas leves por meio da formação complementar do empreendedor em aspectos técnicos e gerenciais e que facilita e agiliza o processo de inovação nas micro e pequenas empresas. Para tanto, conta com espaço físico, pessoal, infra-estrutura e atividades especialmente elaboradas para alojar temporariamente micro e pequenas empresas industriais ou de prestação de serviços (MCT, 1998).

A tipologia das incubadoras empresariais é vasta, porém, considerando-se o objetivo da presente pesquisa, pode-se abordar a seguinte classificação (MCT, 1998): i) incubadora de base tecnológica, que abriga empresas cujos produtos, processos ou serviços resultam de pesquisa científica, para os quais a tecnologia apresenta alto valor agregado; ii) incubadora de empresas de setores tradicionais, que abriga empreendimentos ligados aos setores da economia que detém tecnologias largamente difundidas; e iii) incubadora mista, a abriga ao mesmo tempo empresas de base tecnológica e de setores tradicionais.

No Brasil, o movimento de criação das primeiras incubadoras remonta à década de 1980 quando, por iniciativa da então Secretaria de Indústria, Comércio, Ciência e Tecnologia do Estado de São Paulo, foi instalado o Centro de Desenvolvimento da Indústria Nascente CEDIN, no município de São Carlos. Desde então, a idéia passou a difundir-se, no inicio de forma lenta, adquirindo maior velocidade e amplitude na década de 1990. Inicialmente, cresceram mais em número as incubadoras do tipo tecnológico. Já na década de 1990, a intensidade maior de crescimento relacionou-se às incubadoras tradicionais e mistas.

Nos últimos anos, o número de incubadoras empresariais avolumou-se. Como ilustra a Pesquisa Panorama 2004, publicada pela Associação Nacional de Entidades Promotoras de Empreendimentos Inovadores - ANPROTEC, havia no Brasil, naquele ano, 283 incubadoras distribuídas em 23 Estados e no Distrito Federal. Nessas incubadoras trabalhavam cerca de 10.200 pessoas, considerando os gestores das próprias incubadoras, os empreendedores e os colaboradores das empresas incubadas. Em 2004 havia 1500 empresas incubadas, 1100 graduadas e 1000 associadas (ANPROTEC, 2004).

\section{Desempenho de incubadoras empresariais: uma discussão sobre os principais modelos de avaliação}

A necessidade do estabelecimento de mecanismos de controle das atividades desenvolvidas no interior das organizações já havia sido apontada por Fayol no início do século passado, 
quando apontou o controle como sendo uma das cinco funções universais da administração. A função de controle compreende verificação para apurar se as atividades em curso estão de acordo com aquilo que foi planejado para assegurar o bom desempenho das organizações.

Para os objetivos deste texto a avaliação do desempenho deve ser vista como um conjunto de técnicas adotadas para apurar a eficiência e a eficácia das atividades organizacionais. A eficiência vai tratar da relação entre utilização econômica dos recursos, levando em consideração um determinado nível de satisfação. Por sua vez, a eficácia avalia o resultado de um processo que satisfaz, em maior ou menor intensidade, às expectativas dos usuários. Assim sendo, sugere-se, no caso das incubadoras enquanto unidades organizacionais, que os sistemas de avaliação de desempenho seriam os responsáveis por indicar a efetividade dessa estrutura organizacional em termos sócio-econômicos (DORNELAS, 2002).

Para que se tenha uma noção geral a respeito das reflexões contidas na literatura a respeito da questão da avaliação do desempenho de incubadoras apresenta-se, na Tabela 1, uma síntese das principais propostas, contendo esboços de modelos ou conjuntos de indicadores, aplicáveis para fins de avaliar o desempenho de incubadoras brasileiras.

\begin{tabular}{|c|c|c|}
\hline Modelos & Considerações gerais & Exemplo de variáveis \\
\hline $\begin{array}{l}\text { Proposta do MCT } \\
\text { (1998) }\end{array}$ & $\begin{array}{l}\text { O MCT (1998) sugere ainda que seja efetuada } \\
\text { avaliação do impacto social e econômico da } \\
\text { incubadora em duas fases, quais sejam, quando as } \\
\text { empresas adquirem condição de graduadas, saindo da } \\
\text { incubadora, o que ocorre, em média, após dois anos de } \\
\text { incubação; e quando as empresas graduadas atingem a } \\
\text { maturidade, consolidada após três anos da graduação. }\end{array}$ & $\begin{array}{l}\text { - A eficiência na gestão dos } \\
\text { recursos recebidos; } \\
\text { - A eficácia e o impacto do } \\
\text { empreendimento quanto à } \\
\text { execução dos objetivos e metas } \\
\text { realizados, considerando o } \\
\text { planejamento apresentado. }\end{array}$ \\
\hline $\begin{array}{c}\text { Proposta do PNI } \\
\text { (DORNELAS, } \\
\text { 2002) }\end{array}$ & $\begin{array}{l}\text { O PNI sugere um conjunto de indicadores de } \\
\text { desempenho que, segundo Dornelas (2002), deve ser } \\
\text { variável componente em qualquer programa de } \\
\text { avaliação de incubadoras, visto que é considerado } \\
\text { como referência sobre o assunto no Brasil. O } \\
\text { diferencial desse conjunto de indicadores é o fato de } \\
\text { considerar três fases do ciclo de incubação, quais } \\
\text { sejam, pré-incubação, incubação e pós-incubação, } \\
\text { sendo que para cada uma destas fases criou-se um } \\
\text { grupo pertinente de indicadores (DORNELAS, 2002). }\end{array}$ & $\begin{array}{l}\text { - Pré-incubação: número de } \\
\text { pedidos de registros no INPI - } \\
\text { Instituto Nacional da } \\
\text { Propriedade Industrial, oriundos } \\
\text { de projetos em pré-incubação; } \\
\text { - Incubação: tempo médio de } \\
\text { incubação; taxa de crescimento } \\
\text { anual do faturamento das } \\
\text { empresas incubadas; } \\
\text { - Pós-incubação: taxa de } \\
\text { crescimento do faturamento. }\end{array}$ \\
\hline $\begin{array}{c}\text { Proposta de } \\
\text { Markley e } \\
\text { McNamara (apud } \\
\text { DORNELAS, 2002) }\end{array}$ & $\begin{array}{l}\text { Mensurar impactos econômicos e fiscais gerados por } \\
\text { empresas incubadas e graduadas. }\end{array}$ & $\begin{array}{l}\text { - Retorno do investimento público } \\
\text { em incubadoras a partir do } \\
\text { enfoque da geração de renda e } \\
\text { empregos; investimento público } \\
\text { em incubadoras, versus } \\
\text { arrecadação fiscal das mesmas. }\end{array}$ \\
\hline $\begin{array}{l}\text { Proposta de Morais } \\
\text { (1997) }\end{array}$ & $\begin{array}{l}\text { O modelo visa: a) avaliar o impacto sócio-econômico e } \\
\text { cultural das incubadoras e empresas incubadas no } \\
\text { desenvolvimento regional ou local; b) induzir a } \\
\text { aplicação de técnicas gerenciais no processo de gestão } \\
\text { dos pequenos empreendimentos de forma a fomentar } \\
\text { probabilidades de êxito; c) construir indicadores de } \\
\text { avaliação da performance das incubadoras que sejam } \\
\text { úteis para as instituições apoiadoras desses programas. }\end{array}$ & $\begin{array}{l}\text { - Empresas graduadas por ano; } \\
\text { inovações registradas por } \\
\text { empresa incubada; relação } \\
\text { candidato por vaga na } \\
\text { incubadora }\end{array}$ \\
\hline
\end{tabular}

Tabela 1: Síntese das propostas para a avaliação do desempenho de incubadoras brasileiras

Algumas constatações podem ser extraídas a partir da apreciação, ainda que superficial, dessas propostas: 1) o alcance restrito dos métodos de avaliação correspondentes, seja em termos de sua aplicabilidade às diferentes tipologias de incubadoras, seja em termos do seu 
reconhecimento; 2) o caráter estanque e limitado de cada uma das propostas, visível pela inexistência de pontos de interseção entre as mesmas; 3) a inexistência de uma proposta que possa ser considerada como modelo de avaliação de desempenho de incubadoras, mesmo que sejam de apenas um tipo. Foram essas lacunas que motivaram a realização desta pesquisa, cujo objeto contempla o tipo de incubadoras mistas.

\section{Metodologia}

Esta pesquisa foi realizada entre março/2004 e fevereiro/2005 e contou com o apoio da FAPESP. Seguiu o método qualitativo, com escolha intencional de dois elementos amostrais, brevemente descritos na Tabela 2, investigados em profundidade durante a pesquisa, sendo também do tipo exploratório, pelo seu caráter preliminar, pelo conhecimento relativamente limitado a respeito dos objetos de investigação e pela impossibilidade de extrapolação de seus resultados. O delineamento da pesquisa é o de estudo de casos múltiplos (Yin, 2004).

A escolha por estudar incubadoras mistas se justifica, pois: (a) acredita-se que essa modalidade de incubadora desempenhe importante papel na geração de emprego e renda, oferecendo contribuições para o desenvolvimento local; e (b) segundo a Anprotec (2004), observa-se uma redução na proporção de incubadoras de base tecnológica, ao mesmo tempo em que ocorre um crescimento, também contínuo, no número de incubadoras mistas.

Nos estágios preliminares da pesquisa buscou-se desenvolver um melhor detalhamento dos indicadores propostos por Fonseca (2000). A compreensão e a sistematização de cada indicador foram acompanhadas por busca de fundamentos com base na literatura especializada. Essa fase compreendeu os primeiros seis meses da pesquisa. Uma vez sistematizados os indicadores, foi realizado um teste em duas incubadoras em municípios do interior paulista.

\begin{tabular}{c|c|c|c|c}
\hline Incubadora & Tipologia & Sistema de Gestão & $\begin{array}{c}\text { Número de empresas } \\
\text { incubadas }\end{array}$ & $\begin{array}{c}\text { Número de empresas } \\
\text { graduadas }\end{array}$ \\
\hline $\begin{array}{c}\text { Incubadora } \\
A\end{array}$ & Mista & $\begin{array}{c}\text { FIESP/CIESP, em parceria } \\
\text { com o Sebrae/SP }\end{array}$ & 07 & 20 \\
\hline $\begin{array}{c}\text { Incubadora } \\
B\end{array}$ & Mista & $\begin{array}{c}\text { Gestão ligada à Prefeitura } \\
\text { Municipal }\end{array}$ & 11 & 14 \\
\hline
\end{tabular}

Tabela 2: Perfil das incubadoras investigadas

Como já se explicitou anteriormente, o objetivo central da pesquisa foi o de realizar um teste da aplicabilidade de um conjunto de indicadores para fins de avaliação do desempenho de incubadoras empresariais mistas. Para tanto, foram coletados, através de fontes múltiplas (entrevistas e prospecção documental), dados primários junto às incubadoras selecionadas e às empresas abrigadas. À época da coleta de dados, havia 18 empresas incubadas, às quais foram aplicadas entrevistas semi-estruturadas e questionários fechados, a fim de se avaliar os efeitos do processo de incubação. O número de empresas graduadas, contemplado na Tabela 2, considera o total de empresas que se graduaram desde a fundação de cada uma das incubadoras estudadas. A análise dos dados se valeu do modelo da "escada da abstração analítica". Com a aplicação desse método, os dados são, inicialmente, resumidos e sistematizados pela reconstituição de entrevistas e sinopses dos dados. Na seqüência, os dados são reorganizados e agregados, identificando-se temas e tendências, o que culmina em um esquema explicativo. 


\section{Apresentação do modelo testado}

A contribuição de Fonseca (2002) consiste no agrupamento de indicadores aplicáveis, de um lado, às empresas incubadas e, de outro, às incubadoras, tendo o mesmo propósito de avaliar o desempenho da incubadora enquanto unidade organizacional, como mostra a Figura 1.

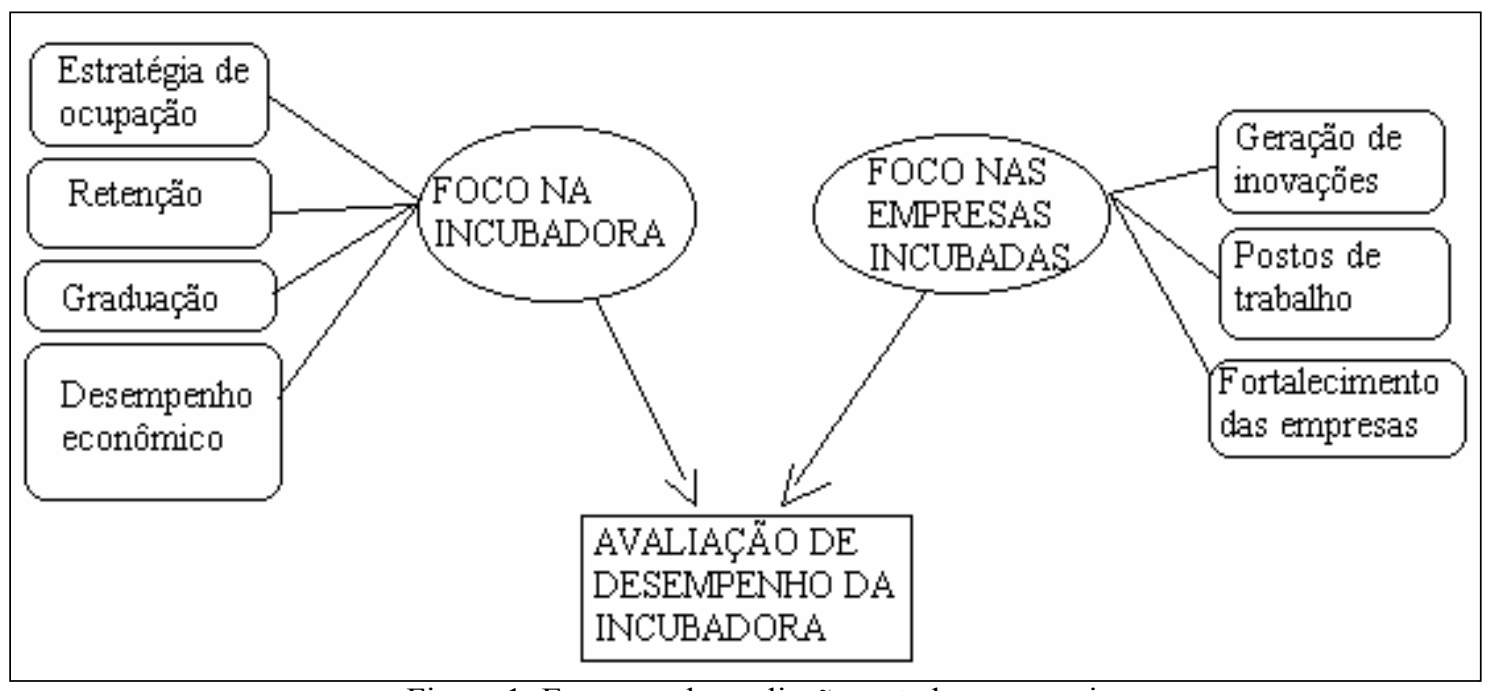

Figura 1: Esquema de avaliação testado na pesquisa

Para uma melhor compreensão do significado de cada indicador são detalhados, nas Tabelas 3 e 4, os seus respectivos conteúdos e variáveis pertinentes, essas últimas orientadoras do processo de coleta de dados.

\begin{tabular}{|c|c|c|c|}
\hline Foco & Indicador & Definição & Principais Variáveis \\
\hline \multirow{4}{*}{$\begin{array}{l}\text { Em dados } \\
\text { das } \\
\text { incubadoras }\end{array}$} & $\begin{array}{l}\text { Estratégia } \\
\text { de ocupação }\end{array}$ & $\begin{array}{l}\text { Diz respeito ao padrão global de } \\
\text { políticas, decisões e ações que } \\
\text { influenciam a forma pela qual a } \\
\text { incubadora seleciona suas unidades } \\
\text { incubadas. Contrapõe dados } \\
\text { referentes à ocupação efetiva com o } \\
\text { planejamento inicial. }\end{array}$ & $\begin{array}{l}\text { - Quantidade de empresas incubadas do } \\
\text { mesmo setor de atividade econômica } \\
\text { - Plano de negócio de empresas } \\
\text { candidatas à incubação. Quantidade de } \\
\text { módulos ociosos. } \\
\text { - Mecanismos de estímulo à demanda por } \\
\text { ocupação. } \\
\text { - Tipo da estratégia de ocupação: } \\
\text { declarada ou não declarada. }\end{array}$ \\
\hline & Retenção & $\begin{array}{l}\text { Este indicador está intimamente } \\
\text { relacionado à capacidade das } \\
\text { incubadoras em reterem suas } \\
\text { empresas incubadas até o estágio de } \\
\text { graduação. Leva-se em conta a } \\
\text { capacidade e a habilidade das } \\
\text { incubadoras em evitar a mortalidade } \\
\text { de empresas incubadas, a saída } \\
\text { prematura ou o desinteresse na } \\
\text { permanência. }\end{array}$ & $\begin{array}{l}\text { - Perfil e intensidade dos serviços de } \\
\text { apoio oferecidos às empresas abrigadas; } \\
\text { - Indices de evasões de empresas; } \\
\text { - Infra-estrutura e utilidades disponíveis; } \\
\text { - Capacitação do quadro de pessoal da } \\
\text { incubadora } \\
\text { - Custos dos serviços partilhados pelas } \\
\text { empresas }\end{array}$ \\
\hline & Graduação & $\begin{array}{l}\text { Avalia a habilidade das incubadoras } \\
\text { em promover a graduação das } \\
\text { empresas incubadas. Somam-se a isto } \\
\text { informações sobre o nível de } \\
\text { sobrevivência de ex-incubadas. }\end{array}$ & $\begin{array}{l}\text { - Quantidade de empresas graduadas } \\
\text { desde a fundação da incubadora; } \\
\text { - Número total de empresas graduadas } \\
\text { desde a fundação da incubadora que } \\
\text { permanecem no mercado; } \\
\text { - Quantidade de empresas graduadas no } \\
\text { último ano; }\end{array}$ \\
\hline & $\begin{array}{l}\text { Desempenho } \\
\text { econômico }\end{array}$ & $\begin{array}{l}\text { O indicador de desempenho } \\
\text { econômico, que diz respeito à } \\
\text { avaliação do grau de autonomia e } \\
\text { sustentabilidade econômica da } \\
\text { incubadora, isto é, considera tanto a } \\
\text { saúde financeira e econômica como a } \\
\text { autonomia na alocação de recursos } \\
\text { pela a incubadora. }\end{array}$ & $\begin{array}{l}\text { - Contraposição entre receita e despesa de } \\
\text { determinado ano base. } \\
\text { - A autonomia do gerente da incubadora } \\
\text { em administrar os recursos disponíveis, } \\
\text { considerando-se o grau de autonomia } \\
\text { disponibilizado pela entidade } \\
\text { mantenedora. }\end{array}$ \\
\hline
\end{tabular}

Tabela 3: Indicadores relacionados às atividades das incubadoras 


\begin{tabular}{|c|c|c|c|}
\hline Foco & Indicador & Definição & Principais Variáveis \\
\hline \multirow{3}{*}{$\begin{array}{l}\text { Em dados } \\
\text { das } \\
\text { empresas } \\
\text { incubadas }\end{array}$} & $\begin{array}{l}\text { Geração de } \\
\text { inovações }\end{array}$ & $\begin{array}{l}\text { Avalia as contribuições das } \\
\text { incubadoras para a geração e a } \\
\text { incorporação de inovações pelas } \\
\text { empresas abrigadas. }\end{array}$ & $\begin{array}{l}\text { - Estímulos das incubadoras à geração de } \\
\text { inovações pelas empresas; } \\
\text { - Geração de inovações organizacionais, } \\
\text { em produtos ou processos durante a } \\
\text { incubação; } \\
\text { - Formalização de inovações no INPI. }\end{array}$ \\
\hline & $\begin{array}{c}\text { Geração de } \\
\text { postos de } \\
\text { trabalho }\end{array}$ & $\begin{array}{l}\text { O indicador de geração de } \\
\text { empregos contempla a variação } \\
\text { dos postos de trabalho das } \\
\text { incubadoras e empresas } \\
\text { abrigadas. }\end{array}$ & $\begin{array}{l}\text { - Evolução do número de postos de } \\
\text { trabalho da própria incubadora; } \\
\text { - Evolução dos postos de trabalho das } \\
\text { empresas incubadas }\end{array}$ \\
\hline & $\begin{array}{c}\text { Fortalecimento } \\
\text { das empresas }\end{array}$ & $\begin{array}{l}\text { Trata-se aqui de uma tentativa de } \\
\text { avaliar a evolução da geração de } \\
\text { renda pelas empresas abrigadas } \\
\text { durante o período de incubação. }\end{array}$ & $\begin{array}{l}\text { - Contraposição entre a evolução das } \\
\text { receitas geradas e despesas incorridas } \\
\text { pelas empresas durante o período de } \\
\text { incubação. }\end{array}$ \\
\hline
\end{tabular}

Tabela 4: Indicadores relacionados às atividades das empresas

\section{Apresentação e discussão dos resultados}

Os dados coletados revelaram que as incubadoras apresentaram um desempenho muito semelhante nos seguintes aspectos: (i) ambas as incubadoras pouco contribuem para um melhor desempenho comercial das empresas abrigadas; (ii) nenhuma das duas incubadoras desenvolve iniciativas para buscar aproximação das empresas com fontes geradoras de inovações, tais como universidades e centros de pesquisa; (iii) ambas as incubadoras apresentaram elevados graus de dependência econômica e financeira em relação às suas instituições mantenedoras. Similaridades à parte, a pesquisa revelou que, com base nas demais variáveis analíticas utilizadas, a incubadora $\mathrm{B}$ apresentou um desempenho significativamente superior ao da incubadora A, o que foi comprovado a partir das seguintes constatações, sintetizadas na Tabela 5:

- a incubadora de $\mathrm{B}$ alcançou maior grau de aderência entre a estratégia de ocupação pretendida e a alcançada;

- as empresas abrigadas em B revelaram um grau de satisfação bem mais elevado com relação aos serviços prestados pela incubadora do que aquelas da unidade A;

- além disso, destaca-se que grande parte das empresas incubadas em B está satisfeita com o espaço físico ocupado (cerca de $90 \%$ ) e com a infra-estrutura fornecida, a qual é superior, em termos qualitativos e quantitativos em relação à infra-estrutura de A;

- o suporte de recursos humanos também apresenta grandes disparidades, notando-se que enquanto a incubadora A conta com apenas três funcionários, B conta com doze, dos quais quatro possuem nível superior completo;

- embora de forma ainda tímida e incipiente, a incubadora B busca realizar algumas atividades tendentes a estimular as empresas a empenharem-se na geração, incorporação e, até mesmo, na formalização de inovações.

Os efeitos dessas disparidades operacionais foram diretamente observados na avaliação do comportamento das empresas abrigadas, destacando-se os seguintes aspectos:

- a incubadora A apresentou um índice mais elevado de mortalidade de empresas vis-à-vis os resultados encontrados na incubadora B;

- quando investigadas as empresas sob a ótica do indicador de fortalecimento (econômico), o desempenho unidade B também mostrou-se substancialmente superior ao da unidade A; 
- tomando-se o comportamento das empresas já graduadas, a pesquisa apurou que as empresas que foram abrigadas na incubadora A demonstraram maior fragilidade de sobrevivência do que as graduadas na incubadora B;

- com relação à geração de postos de trabalho durante o período de incubação, a incubadora B gerou uma média de empregos por empresa incubada próxima de sete, enquanto a média encontrada na incubadora A situou-se em um patamar inferior a cinco.

\begin{tabular}{|c|c|c|c|}
\hline Foco & Indicador & $\begin{array}{l}\text { Unidade com } \\
\text { o melhor } \\
\text { desempenho }\end{array}$ & Justificativas \\
\hline \multirow{4}{*}{$\begin{array}{l}\text { Em dados das } \\
\text { incubadoras }\end{array}$} & $\begin{array}{l}\text { Estratégia de } \\
\text { Ocupação }\end{array}$ & B & $\begin{array}{l}\text { - Cerca de } 70 \% \text { das empresas abrigadas em B têm perfil } \\
\text { alinhado com a estratégia de ocupação declarada pela } \\
\text { incubadora; } \\
\text { - na incubadora A, o alinhamento entre a estratégia de } \\
\text { ocupação declarada e a realizada cai para } \\
\text { aproximadamente } 50 \%\end{array}$ \\
\hline & Retenção & B & $\begin{array}{l}\text { - } 100 \% \text { dos dirigentes das empresas incubadas em B estão } \\
\text { satisfeitos com o processo de incubação, sendo que } 90 \% \\
\text { destes estão satisfeitos com o tamanho do box ocupado; e } \\
\text { nenhuma empresa abrigada em B “morreu” durante a } \\
\text { incubação. } \\
\text { - Já na incubadora A, apenas } 70 \% \text { dos entrevistados estão } \\
\text { satisfeitos com o processo de incubação e } 10 \% \text { de todas as } \\
\text { empresas que iniciaram o processo de incubação } \\
\text { "morreram" antes de concluí-lo; }\end{array}$ \\
\hline & Graduação & B & $\begin{array}{l}\text { - Com relação a B, } 18 \text { empresas já se graduaram, sendo que } \\
\text { todas se mantêm em atividade no mercado; } \\
\text { - A incubadora A já graduou } 20 \text { empresas desde sua } \\
\text { fundação, das quais } 18 \text { encontram-se em atividade, isto é, } \\
10 \% \text { delas "morreram"; }\end{array}$ \\
\hline & $\begin{array}{l}\text { Desempenho } \\
\text { econômico }\end{array}$ & B & $\begin{array}{l}\text { - A incubadora B possui um maior grau de autonomia na } \\
\text { alocação de seus recursos e cerca de } 10 \% \text { de sua receita } \\
\text { mensal não está vinculada a repasses de outras } \\
\text { instituições; } \\
\text { - A incubadora A não possuía nem ao menos informações } \\
\text { contábeis e projeções de receita e despesa, pois tais } \\
\text { controles são realizados e centralizados na sede de sua } \\
\text { instituição mantenedora. }\end{array}$ \\
\hline \multirow[t]{3}{*}{$\begin{array}{c}\text { Em dados das } \\
\text { empresas } \\
\text { incubadas }\end{array}$} & $\begin{array}{l}\text { Geração de } \\
\text { inovações }\end{array}$ & B & $\begin{array}{l}\text { - Apenas } 34 \% \text { dos abrigados em A informaram que tal } \\
\text { incubadora estimula a geração de inovações. Já em B, } \\
\text { cerca de } 75 \% \text { informaram ser incentivados a inovar em } \\
\text { produtos ou processos; } \\
\text { - No que tange à geração efetiva de inovações durante o } \\
\text { processo de incubação, temos que, das oito empresas } \\
\text { abrigadas na incubadora A, } 62,5 \% \text {, aproximadamente, } \\
\text { afirmaram ter inovado. } \\
\text { - Na incubadora B, a inovação efetiva foi constatada em } \\
\text { nove das onze empresas abrigadas, o que corresponde a } \\
\text { aproximadamente } 81 \% \text { das unidades incubadas à época da } \\
\text { pesquisa. }\end{array}$ \\
\hline & $\begin{array}{l}\text { Geração de } \\
\text { Empregos }\end{array}$ & B & $\begin{array}{l}\text { - Na incubadora A, o processo de incubação das empresas } \\
\text { estudadas gerou } 38 \text { novos postos de trabalho, isto é, uma } \\
\text { média de cinco novos postos de trabalho por empresa } \\
\text { incubada. Já em B, durante a incubação as empresas } \\
\text { abrigadas criaram novos } 80 \text { postos de trabalho, o que } \\
\text { resulta em uma média de quase sete novas vagas por } \\
\text { empresa }\end{array}$ \\
\hline & $\begin{array}{c}\text { Fortalecimento } \\
\text { das empresas }\end{array}$ & B & $\begin{array}{l}\text { - Cerca de } 15 \% \text { das empresas incubadas em A apuraram } \\
\text { prejuízo no período base avaliado, fato que não ocorreu } \\
\text { com a incubadora B }\end{array}$ \\
\hline
\end{tabular}

Tabela 5: Síntese da análise comparativa entre os desempenhos das incubadoras 
É possível observar facilmente na Tabela que, sob qualquer das óticas de análise ou, com base em qualquer um dos indicadores sugeridos, a incubadora B revelou um desempenho superior ao da incubadora A. Como não era objetivo da pesquisa avaliar o desempenho das incubadoras, mas avaliar a possibilidade de aplicação dos indicadores utilizados, para fins, aí sim, de avaliar o desempenho de incubadoras, o que é possível sugerir a partir dos resultados contidos na Tabela 5 é que existe uma aparente consistência entre os indicadores testados. Não fosse assim, diferentes indicadores poderiam apontar resultados contraditórios.

\section{Considerações Finais}

Uma primeira observação é quanto ao alcance limitado da pesquisa. A amostra utilizada se revelou restrita para que se possa sustentar qualquer tipo de inferência conclusiva. Isso reforça o caráter exploratório da pesquisa, já destacado anteriormente. Daí que qualquer afirmação deva ser considerada como meramente indicativa ou sugestiva. Feita essa ressalva, é possível apontar as seguintes reflexões a respeito dos resultados da pesquisa.

Uma primeira é que, aparentemente, os indicadores testados são consistentes com o propósito de se avaliar incubadoras. Demandam, no entanto, o teste em um número maior de unidades para uma melhor validação. É necessária, ademais, uma reflexão aprofundada a respeito de cada indicador, especialmente com vistas ao estabelecimento de maior volume de métricas e parâmetros quantitativos. Outra consideração é quanto ao uso, como fontes analíticas, das incubadoras e das empresas abrigadas. Aparentemente o que a pesquisa revelou é que os indicadores que usam dados das incubadoras como suporte são mais reveladores do desempenho de processos. Já os indicadores que se apóiam em dados coletados junto às empresas abrigadas parecem revelar o desempenho das incubadoras em termos dos resultados últimos das suas atividades.

Aspectos que a pesquisa não conseguiu revelar são os referentes a eventuais relações de causalidade entre processos e resultados. Em outras palavras, uma das frentes de investigação que permaneceu inexplorada, e aí fica indicada uma sugestão para a sua continuidade, concerne à busca da compreensão de quais processos internos às incubadoras possam ter maior ou menor poder de influência sobre o desempenho das empresas. Ficam, portanto, registradas novas possibilidades e necessidades, para a continuidade e o aprofundamento desta frente de pesquisa, seja com vistas a rever/ajustar ou validar a proposta de modelo de avaliação apresentada neste texto, seja para contribuir a engendrar uma sistemática para a avaliação de desempenho de incubadoras.

\section{Bibliografia}

ANPROTEC. (2004). Pesquisa Panorama 2004. Brasília: Anprotec.

DORNELAS, J.C.A. (2002) Planejando incubadoras de empresas. Rio de Janeiro: Campus.

FONSECA, S. A. (2000). Avaliação do processo de implantação e do desempenho de incubadoras empresariais mistas: um estudo de caso no Estado de São Paulo. Tese (doutorado em Administração). FEA/USP, São Paulo.

KAHANE, B.; TZVI, R. (2005). Innovation projects in Israeli incubators: categorization and analysis. European Journal of Innovation Management. Vol.8, n.1, p.91-103.

MCT. (1998). Manual para a implantação de incubadoras de empresas. Brasília: MCT.

MORAIS, E. F. C. (1997). Manual de acompanhamento e auto-avaliação de incubadoras. Brasília: CDT.

YIN, R. (2004). Estudo de caso: Planejamento e Método. São Paulo: Bookman. 